$33 \mathrm{~mm} . \mathrm{MgSO}_{4} ; 500 \mathrm{c.cm}$. of normal saline fluid were then injected. Immediately after the injection the pressures were: femoral artery, $126 \mathrm{~mm}$. Hg ; portal vein, $370 \mathrm{~mm}$. $\mathrm{MgSO}_{4}$; rena cava, $225 \mathrm{~mm}$. $\mathrm{MgSO}_{4}$. Ten minutes later the pressures were still very much raised: femoral artery, $122 \mathrm{~mm} . \mathrm{Hg}$; portal vein, $198 \mathrm{~mm} . \mathrm{MgSO}_{4}$; vena cava, $103 \mathrm{~mm} . \mathrm{MgSO}_{4}$. At the same time, as has been shown by Cohnheim and other observers, the arterioles are dilated, and the velocity of the circulating blood and total blood sent out by the heart at each beat are very largely increased-all factors tending (while arterial pressure is normal) to send up the pressure in the capillaries generally.

We have, then, in hydræmic plethora two conditions which might cause an increase in the lymph production-viz, (a) the blood is more watery; $(b)$ the capillary pressures are increased. Which of these two factors is responsible for the increased flow of lymph? This question is easily answered by studying the effects of simple hydræmia. If instead of injecting normal saline directly into the animal we first withdraw $200 \mathrm{c.cm}$. of blood and then replace it by the injection of an equal bulk of normal saline, and then repeat the process, we may attain a high degree of hydræmia without any increase in the total bulk of the circulating fluid and without any alteration in the capillary pressures. Under these circumstances, although the blood is excessively watery, there is practically no increase in the amount of lymph produced, as was pointed out by Cohnheim many years ago. It seems, then, that the degree of dilution of the blood has no influence on the production of lymph, the only essential factor being the condition of the intracapillary pressure.

Ancmia.-If the animal be simply bled without replacing the lost blood by the injection of fluid, there is a general fall of pressure in the capillaries. Associated with this fall we find that the lymph flow from the thoracic duct is very largely diminished, and there is at the same time evidence of a rapid reabsorption of fluid from the connective tissue spaces, so that the plasma of the blood is increased relatively to the corpuscles, and the specific gravity of the whole blood sinks considerably. It is evident, then, that it is by means of this sensibility to pressure or permeability of the ressel walls that the volume of the circulating blood is maintained nearly constant. Perhaps to ardent vitalists the teleological significance of this dependence of lymph production on capillary blood pressures may serve as the best recommendation of the doctrine grounded by Ludwig, which the hard tests of experiment have compelled me to adopt. It must be remembered, however, that if we say that lymph is formed by a process of filtration, we are still merely dealing with a hypothesis. The fact which I think I have established by my experiments is that, in the abdominal organs at least, lymph production is a function of the capillary blood pressure.

In my next lecture I shall consider how far this conclusion is supported by the results of nerve section and stimulation, and of the injection of lymphagogues.

\section{BICHROMATE OF POTASSIUM AS A REMEDY IN GASTRIC AFFECTIONS.}

BY THOS, R. FRASER, M.D., LL.D., F.R.S., F.R.C.P. EDIN., PROFESSOR OF MATERIA MEDICA AND CLINICAL MEDICINE IN THE UNIVERSITY OF EDINBURGH.

(Communicated to the Eleventh International Medical Congress, held in Rome, April, 1894.)

NoTWITHSTANDING the assertion made in 1883, and supported by much illustrative evidence, by so high an authority as Vulpian, ${ }^{1}$ of the value of bichromate of potassium in the treatment of several forms of gastric affection, this substance has not yet gained a position among the many substances that are used in the treatment of these affections, and but meagre reference is made it to in only a few works on medicine and materia medica. Previously to Vulpian's recommendation it had been used by internal administration as an emetic, and with varying success in syphilitic, bronchopulmonary, and nervous disorders; and Drysdale had advo. cated its employment in affections of nearly all the important organs of the body. Having in 1884 treated with gratifying

1 Journal de Pharmacie et de Chimie, 5me série, tome viii., 1883, pp. 215 and 321. success a case of persistent gastric disorder by the administration of small doses of bichromate of potassium, I have since that time administered it in a large number of cases. The results have been so favourable that I feel myself justified in now stating my opinion of the therapeutic value of this substance and in briefly recording a number of the cases of gastric disorder in which it was used by me. With a few exceptions the cases have been those of hospital patients. While such patients give the best opportunity for determining the effects of medicinal substances, it is not to be overlooked that, in some respects, they are also placed in more favourable conditions for successful treatment than the majority of private patients. In order to simplify the therapeutic problem the medicinal treatment was as far as possible limited to the administration of bichromate of potassium. This limitation, however, could not be adbered to in all cases but only those cases will be described in which the drug alone was administered, or with the addition of other remedies, such as purgatives, rendered necessary by the circumstances of the patient, and unlikely to obscure the effects of the chief remedy. I have recorded the cases in two groups-the first group comprehending eighteen cases of various forms of dyspepsia unassociated with evidence of gastric ulcer, and the second group ten cases in which distinctive symptoms of ulcer had been present at some previous time.

\section{Group 1.-DYSPEPSIA.}

CASE 1.-A miner twenty years of age. Symptoms and duration: Anorexia; pain in the stomach fifteen minutes after food, with distension; frequent nausea and occasional vomiting after food, diarrhoea and headache. Tenderness (great) at upper part of epigastrium. These symptoms had been present for five months. Treatment: Milk diet; Oct. 28th, bichromate of potassium ( $\frac{1}{10}$ gr.) twice daily till Nov. 13th, and thrice daily till Nor. 20th. Effects and time of production: On Nov. 8th decidedly improved ; on 18th on convalescent diet and no symptom present except slight and brief pain after food, but not if patient remained resting. Discharged cured on Nov, 22nd.

CASE 2.-Domestic servant twenty-two years of age. Symptoms and duration : Had been dyspeptic for many years, but this attack commenced a month ago. Anorexia, headache, frequent vomiting, pain and tenderness in gastric region, and constipation. Treatment : Oct. 18th, milk diet, cascara extract night and morning, bichromate of potassium ( (1) gr.) thrice daily. Effects and time of production : On Oct. 2lst much better and no pain after food ; on Oct. 24th no tenderness or other symptom; on Oct. 25th on convalescent diet, and on Nov. 1st dismissed, having gained several pounds in weight.

CASE 3.-Printing machine worker twenty years of age. Symptoms and duration: Had gastric ulcer when nineteen years of age. Present illness began seven days before admission; epigastric pain on taking food, with vomiting half an hour afterwards, producing relief of pain ; great weakness, tenderness on palpation, constipation. Treatment : Oct. 4th, cascara extract, milk diet ; Oct. 21st, bichromate of potassium ( $\frac{1}{12} \mathrm{gr}$.) thrice daily. Effects and time of production : Before Oct. 21st pain and tenderness were continuous, with occasional vomiting; after bichromate commenced pain, tenderness, and sickness quickly disappeared, and the patient was dismissed cured on Oct. 29th.

CASE 4.-Grocer's assistant fifteen years of age. Symptoms. and duration : Severe headache, with nausea and vomiting, for twelve months. Treatment : From Dec. 10th to 18th bismuth, rhubarb and soda; Dec. 18th, bichromate of potassium ( $\left.\frac{1}{2} \mathrm{gr}\right)$ thrice daily. Effects and time of production: Improved considerably from Dec. 10th to 18th, but often had headache, nausea, and vomiting; bichromate was then substituted, after which headache and vomiting altogether disappeared and nausea after food rapidly lessened, till he was dismissed cured on Dec. 31st.

CASE 5.-A coal miner forty-one years of age. Symptoms and duration: Eight years ago gastralgia, lasting for a year; one year ago gastralgia for one month; one month ago present illness, consisting of sensations of weight and pain in stomach about an hour after food, eructations, vomiting every two or three days, epigastric tenderness and constipation. Treatment: From Jan. 7th to Jan. 12th exalgin Jan. 12th, bichromate of potassium ( $\frac{1}{12}$ gr.) thrice daily. Effects and time of production: No improvement till Jan. 12th ; subsequently considerable alleviation, and ultimately disappearance of romiting. The patient was dismissed, much improved, on Jan. 19th. 
CASE 6.-A woman twenty-three years of age. Symptoms and duration : Had been dyspeptic for years. On admission suffered from flatulence, epigastric pain and tenderness, and occasional vomiting, which had all been present in severe form for four months. Treatment: From Feb. 24th to March 7th extract of cascara ; from March 7th to 16th bichromate of potassium ( $\frac{1}{12}$ gr.) thrice daily. Effects and time of production : Improved to March $7 \mathrm{th}$, but still tenderness, flatulence, and pain after food. On March 9th there was no longer tenderness or pain after food ; dismissed, cured, on March 17th.

CASE 7.-A brass-finisher nineteen years of age. Symptoms and duration: For several months pain immediately after food, lasting for about an hour, flatulent distension, epigastric tenderness, and some enlargement of stomach ; patient also had presystolic mitral disease. Treatment: March 10th bichromate of potassium ( $\frac{1}{12}$ gr.) thrice daily. Effects and time of production: On March 18th no pain after food, flatulence, or epigastric tenderness. There were no further gastric symptoms, although patient was kept in hospital till April 5th because of the cardiac disease.

CASE 8. - A woman, a lithographer, twenty years of age. Symptoms and duration: For four months anorexia, discomfort, nausea, pain, and romiting after food; slight anæmia ; constipation. Treatment: From Feb. 11th to March 3rd cascara, cod-liver oil, and ferrous chloride; March 3rd, bichromate of potassium (r gr.) thrice daily. Fffects and time of production: The anæmia soon disappeared. The gastric symptoms persisting, bichromate was administered. The dyspepsia improved, until in five days fish and chicken were taken without any discomfort; and she was dismissed, cured, a few days afterwards.

CASE 9.-A printer fifty years of age. Symptoms and duration : For a year epigastric pain and tenderness, nausea and romiting after food, flatulence, constipation; also suffers from aortic stenosis, and had an alcoholic history. Treatment: From Oct. 28th to Nov. 4th calomel and compound jalap powder at first, and then compound tincture of cardamom; from Nov. 4th to 10th bichromate of potassium ( $\frac{1}{12}$ gr.) thrice daily. Effects and time of production : No distinct improvement evident till Nov. 6th, when, for the first time, no pain or nausea. On the 14th no symptom of gastric disorder. Dismissed, cured, on Nov. 16th.

CASE 10.-A woman twenty-five years of age, a worker in an indiarubber manufactory. Symptoms and duration : For two years dyspeptic symptoms, sometimes severe. On admission anorexia, thirst, gastric pain and tenderness, occasional vomiting, acid eructations after food, flatulent distension, and constipation. Treatment: On Dec. 11th bichromate of potassium ( $\frac{1}{12}$ gr.), increased to $\frac{1}{8} \mathrm{gr}$. on Dec. 16 th ; liquid extract of cascara for several days. Effects and time of production: In five days after beginning the bichromate of potassium ernctations and gastric pain had disappeared, and in ten days epigastric tenderness could not be elicited. Patient was dismissed, while taking light diet without discomfort, on Jan. 3rd.

CASE 11. - A horse-driver fifty-two years of age. Symptoms and duration: For about six months anorexia, vomiting immeaiately after food and epigastric pain and tenderness. There were moderate enlargement of the liver and an alcoholic bistory. Treatment : Aug. 9th, bichromate of potassium (1- gr.) thrice daily. Fffects and time of production : Vomiting and epigastric pain and tenderness gradually diminished, and had disappeared when patient was dismissed from hospital on Aug. 17th, but anorexia was still present.

CASE 12. -A domestic servant twenty-five years of age. Symptoms and duration : For four month severe gastric pain, with nausea, lasting about six hours daily, apparently excited by food, frequent vomiting, anorexia, and epigastric tenderness. Treatment: June 9th, bichromate of potassium $\left(\frac{1}{\&} \mathbf{r}_{\text {. }}\right)$ thrice daily. Effects and time of production : Gradual improvement, unvil in nine days epigastric pain, tenderness and vomiting had disappeared. After the symptoms had been absent for twelve days, owing to an error in diet, they returned for seven days. They afterwards again entirely disappeared, and the patient was dismissed, cured, on July 17th.

CASE 13. - A shop girl fourteen years of age. Symptoms and duration : For one month sickness and vomiting after food, and for two months epigastric pain with anorexia. There was also epigastric tenderness. Treatment : Feb. 21st, bichromate of potassium ( $y^{2}$ gr.) thrice daily. Effects and time of prodnction: Before bichromate treatment, the patient improved considerably on milk diet, and improvement rapidly increased after bichromate, so that in fourteen days all the symptoms had disappeared.

CASE 14.-A nursery maid eighteen years of age. Symptoms and duration: For six weeks pain and frequently romiting an hour after food, epigastric tenderness, and slight constipation; there was also considerable anæmia. Treatment: Milk diet Nov. 3rd, bichromate of potassium ( $\frac{1}{5}$ gr.) thrice daily. Effects and time of production: In four days all the dyspeptic symptoms had disappeared, except that pain and nausea occurred unless patient lay down after meals. She was dismissed, cured of the gastric symptoms, on Nor. 14th.

CASt 15. - A general servant twenty years of age. Symptoms and duration: For three years symptoms of dyspepsia. Now anorexia, thirst, sensations of distension and pain immediately after food, followed by nausea and romiting. There were also constipation and slight jaundice, and the stomach was somewhat enlarged. The patient was anæmic. Treatment : From Sept. 12th to Oct. 20th bismuth and iron; from

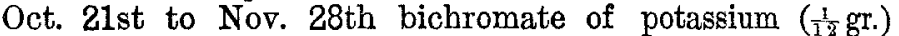
thrice daily. Effects and time of production: Under iron and bismuth the dyspeptic symptoms, though improved, were not materially so. Two days after commencing bichromate of potassium an improvement was observed. In four days sickness, nausea, and epigastric tenderness had disappeared, though on several occasions during a few subsequent days pain occurred after food.

CASE 16.-A millworker twenty-five years of age. Symptoms and duration: For several years occasional attacks of vomiting and faintness, followed by headache; shortly before admission these attacks occurred weekly, and were preceded by abdominal distension and pain following food. Treatu ment: Nov. 9th, bichromate of potassium ( $\frac{1}{12}$ gr. ) thrice daily ; on the 15th also extract of cascara nightly. Effects and time of production: Epigastric pain soon disappeared, and the patient was dismissed on Nov. 19th free from symptoms.

CASE 17.-A domestic servant eighteen years of age. Symptoms and duration: For eighteen months pain in the stomach and vomiting, with several intervals of partial relief; on admission above symptoms, which had been present in severe form for about four months, and, in addition, marked epigastric tenderness and moderate constipation. Treatment: Jan. 4th, extract of cascara night and morning; the 8th, bichromate of potassium ( $\frac{1}{12} \mathrm{gr}$.) thrice daily, increased on the 10th to $\frac{1}{\mathrm{~s}}$ gr. ; milk diet from Jan. 3rd to the 19th, when farinaceous foods were added; on Feb. 3rd convalescent diet with fish and white animal food was taken without discomfort. Effects and time of production: No material improvement until Jan. 11th, when pain after food was lessened, and it disappeared on the 17th, bat returned for brief intervals after food from the 24th to the 27th, and did not recur afterwards; epigastric tenderness could be elicited only by deep percussion on the 28th, and it altogether disappeared on Feb. 1st; the patient was dismissed cured on the 13th.

CASE 18. - A domestic servant twenty-two years of age. Symptoms and duration: For three months anæmic and dyspeptic symptoms, the latter becoming gradually more severe, until for three weeks previously to treatment the patient vomited after every meal, except when lying down; she had also anorexia, epigastric pain, and tenderness; she had considerable anæmia. Treatment: Oct. 12th, bichro. mate of potassium ( $\frac{1}{12}$ gr.) thrice daily, increased on Nov. 3rd to $\frac{1}{6}$ gr. thrice daily, and continued to the 16 th, when ferrous chloride was substituted on account of the anæmia. Effects and time of production: The gastric symptoms rapidly improved until, in nine days, they had entirely disappeared, while the anæmia had not materially improved; the blood, however, became normal soon after iron was administered.

\section{Group 2.-Gastric Ulcer.}

CASE 1.-A domestic servant twenty-seven years of age. Symptoms and duration: Three years and three months ag pain half an hour after food, lasting about an hour and a half, and flatulence. Soon vomiting, the matters later containing blood, but not for some months past; headache and constipation. Symptoms and weakness more urgent latterly. Treatment: April 13th, bichromate of potassium ( $\frac{1}{10}$ gr.) thrice daily; Carlsbad salts every morning milk diet. Effects and time of production: On April 25t no longer any nausea or vomiting, and pain after food less severe and of shorter duration. On May 8th all gastric symptoms had disappeared, and light diet was taken. She remained in hospital for another fortnight, and when 
dismissed was taking almost ordinary diet, and had gained one stone in weight.

CASE 2.-A nursery maid aged twenty-seven. Symptoms and duration: Dyspepsia for several years. Two years ago persistent pain in stomach, much increased by food, nausea, frequent vomiting, containing blood a year ago, constipation and great feebleness. On admission above symptoms with epigastric tenderness, flatulent distension, and acid eructations. Treatment: March 14th, bichromate of potassium

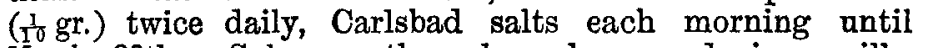
March 30th. Subsequently, also aloes and iron pills. Effects and time of production: Vomiting, which before treatment occurred in hospital daily, and frequently several times a day, became less frequent and ceased on March 26th. The patient was dismissed cured on April 9th.

CASE 3. - A domestic servant aged twenty-five. Symptoms and duration: Eight, and also three, years ago had been severely ill with gastric symptoms ; six weeks before admission pain and sickness occurred; and a fortnight before admission the patient began to vomit after every meal, the vomited matter frequently containing blood. In addition suffered from anorexia, constipation, and epigastric tenderness. Treatment: June 20th, extract of cascara nightly, and bichromate of potassium ( $\frac{1}{12}$ gr.) thrice daily. Effects and time of production: Vomiting last occurred on June $24 \mathrm{th}$, but nausea, especially after meals, continued until the 26th. Pain and tenderness had disappeared on June 30th. Patient was dismissed, free from gastric symptoms, on July 4th.

CASE 4. -A woman thirty-two years of age, a millworker. Symptoms and duration: About fifteen months before admission abdominal pain with distension and eructations, followed by frequent vomiting, containing blood three months before admission, great pain in epigastrium and thorax, epigastric tenderness, and constipation. In addition to above considerable enlargement of the stomach was found to be present. Treatment : From Jan. 26 th to Feb. 5th assafoetida, cardamoms, and cascara. On Feb. 6th bichromate of potassium ( $\frac{1}{12}$ gr.) thrice daily. Subsequently, ferrous chloride. Effects and time of production : Rapid improvement, so that on F'eb. 12th no gastric symptoms were present except occasional slight epigastric pain. This last symptom disappeared in a few days, and patient was dismissed, cured, on March 3rd.

CASE 5. - A woman aged twenty, a cook. Symptoms and duration: For several years flatulence and eructations after food. Six months before admission began to vomit occasionally, and one month before admission frequently, with blood in vomited matter; also constant epigastric pain increased by food, nausea, anorexia, constipation, and epigastric tenderness; patient likewise suffered from molluscum fibrosum. Treatment: From Jan. '10th to 17th bismuth, rhubarb, and soda. Jan. 17th, bichromate of potassium ( $\frac{1}{12}$ gr.) thrice daily. Milk diet until Jan. 24th. Hffects and time of production: On Jan. 20th distinct improvement, but epigastric tenderness was still present. On Jan. 24th all gastric symptoms were absent, and milk diet was departed from.

CASE 6.-A woman aged twenty, a professional dancer. Symptoms and duration: Had romiting of blood a year before admission. Three weeks before admission fainted several times, and vomited a little blood; since then she had vomited several times daily, without blood, about two hours after food ; suffered from epigastric pain after food, constipation, and considerable epigastric tenderness. Treatment: From Jan. 13th to 17th bismuth, rhubarb, and soda; but pain and vomiting were not removed. From Jan. 17th to Feb. 21st bichromate of potassium ( $\frac{1}{2}$ gr.) thrice daily. Again, from March 3rd to 24th bichromate in above doses. Effects and time of production : On Jan. 18th no pain, vomiting, or nausea. On Feb. 27th (bichromate had been stopped on Feb. 21st) a recurrence of pain, nausea, and vomiting. From March 5th to March 24th no symptoms of gastric disorder (bichromate was again being taken). Patient was dismissed, free from gastric symptoms, on March 24th.

CASE 7.-A labourer thirty-seven years of age, employed in a brewery. Symptoms and duration: Gastric pain and romiting at intervals for eight years. Present attack about ten days before admission; great gastric pain and vomiting after food, the vomited matter containing blood; flatulence, acid eructation, constipation, and epigastric tenderness. After admission all above were present except vomiting. Treatment : From March 5th to 11th bismath, rhubarb and soda; from March 11th to 30th bichromate of potassium $\left(f_{2} g r.\right)$ thrice daily. Effects and time of production: Some slight temporary relief of pain between March 7th and 11th. On March 13th pain greatly lessened ; and all pain, tenderness and nausea had disappeared on March 18th. Patient was put on convalescent diet on March 19th. On the 21st and 22 nd there was slight pain for a short time which did not recur, and patient was dismissed on March 30th entirely free from pain, nausea or epigastric tenderness.

CASE 8.-A woman twenty-nine years of age, a cook. Symptoms and duration : A month before admission hæmatemesis with tarry ejections. On admission thirst, moderate constipation, epigastric pain increased by food, epigastric tenderness, and anæmia. No vomiting after admission. Treatment : Oct. 14th, extract of cascara each night; Oct. 20th, bichromate of potassium ( $\frac{1}{12}$ gr.) thrice daily till Nov. 12th ; milk diet till Oct. 21st; afterwards gradually increased to convalescent diet, and on Nov. 8th to full diet: Effects and time of production: On Oct. 24th all stomach pain had disappeared. On Nor. 1st no epigastric tenderness was present.

CASE 9.-A woman forty-seven years of age, a cook. Symptoms and duration: Abont five years ago romiting after food, from which she recovered. Four months before admission vomiting recurred, with severe gastric pain following food, and blood was present on more than one occasion. Patient was very feeble, there was epigastric tenderness, and the stomach was moderately enlarged, and a hard small mass could be felt near the pyloric extremity. Treatment: June 20th, bichromate of potassium ( $\frac{1}{5} \mathrm{gr}$., increased on the 25 th to $\frac{1}{6}$ gr.) thrice daily; milk diet from June 14th till July 24th. Effects and time of production : Vomited thrice on June 20th, and daily till June 24th. Since this date there has been no further vomiting or pain. On July 9th epigastric tenderness had disappeared. She was able to eat white flesh without discomfort before her dismissal on Aug. 3rd, when she had gained seventeen pounds in weight.

CASE 10.-A married woman thirty-five years of age. Symptoms and duration: About nine months before admission pain, nausea, and vomiting after food. Recovered in about six weeks. Symptoms returned in more severe form two months before admission. Pain came on chiefiy an hour after food, even diluted milk, and was followed by nausea and vomiting. Since admission blood was present on two occasions. There was also much epigastric tenderness and constipation. Treatment: May 7th, bichromate of potassium ( $\frac{1}{6}$ gr. ) thrice daily. Milk diet till May 21st; gradually improved to convalescent diet. Effects and time of production: Vomiting, which previously occurred daily, ceased on May 13th until May 22nd, when one attack of romiting occurred, but without pain. From this time improvement was continued without interruption; appetite, strength, and weight were recovered, and gastric symptoms were entirely absent when she left hospital on June 2nd.

While the doses administered in the above cases have varied from $\frac{3}{12} \mathrm{gr}$. to $\frac{1}{6} \mathrm{gr}$. (from 0.005 to 0.01 gramme) thrice daily, it will be observed that in the greatest number of the cases the smallest of these doses was administered, and was found sufficient. The dose should be given during fasting and in as empty a condition of the stomach as possible. The administration was effected in the form of pill or solution; and no difficulty was experienced by the patient in the taking of a simple solution in water, although occasionally, and especially with the larger doses, flavouring agents were added, such as syrup of tolu or of orange. An examination of these records shows that bichromate of potassium is capable of relieving, and often in a short time of removing, the entire group of symptoms-if we except constipation and anæmia-encountered in dyspepsia, and especially pain, nausea, vomiting and gastric tenderness. Taking into account the supposed relationship between disorders of the alimentary canal and anæmia, it might by some have been expected that an agent which is decidedly curative in dyspepsia would, at the same time, exert a curative influence in anæmia. Several of my cases, however, have shown that this is not so, and have thus given evidence that the therapeutic benefit is the result of an action restricted to the stomach. Case 18 (Group 1) serves to illustrate this. On Oct. 12th, when treatment with bichromate of potassium was commenced, an examination of the blood showed that the hæmocytes numbered $4,300,000$, and that the hæmoglobin amounted to 40 per cent. All gastric symptoms had disappeared on Oct. 21st, when the hæmocytes numbered $4,100,000$, and the hæmoglobin amounted to 38 per cent. Bichromate of potassium was continued until Nov. 16th, and even then, although the patient had for some time been eating 
well and had gained weight, the hrmocytes numbered $3,700,000$ and the hæmoglobin amounted to 52 per cent. On this date ferrous chloride was substituted for bichromate of potassium and on Nov. 25th the hæmocytes numbered $5,000,000$ and the hæmoglobin amounted to 79 per cent.

In a few cases of acute gastric ulceration with hæmatemesis in which I have given bichromate of potassinm the results were not favourable, as it did not succeed in checking the bleeding. Indeed, I find that its astringent action is very slight, for a solution of egg albumen, which was rendered hazy by a 0.01 per cent. solution of nitrate of silver, was not distinctly changed by a 3 per cent. solution of bichromate of potassium, and was rendered only slightly hazy by a 4 per cent. solution. At the same time bichromate of potassium possesses a strong anti-putrefactive power, which is exhibited in albuminous, saccharine, and phosphatic urines even with a 001 per cent. solution. This action probably constitutes one of the causes of its anti-dyspeptic therapeutical value, but there are undoubtedly other causes, such as a direct or indirect analgesic action, and probably a selective action on the nutrition or function of certain histological structures, which I am now engaged in endeavouring to determine.

Edinburgh.

\section{A METHOD OF EXCISING THE PROSTATE.}

BY JAS. H. NICOLL, M.B. \& C.M. GLASG.,

DISPENSARY SURGEON, GLASGOW WESTERN INFIRMARY; SURGEON, GLASGOW CENTRAL DISPENSARY, ETC.

THE following is a brief account of a method of prostatectomy which appears to offer certain considerable advantages over those methods already in use of which I have been able to find published records. Prostatectomy now ranks amongst formally recognised surgical operations, and few surgeons can have serious doubts as to its ultimately being widely practised. At present in its infancy, it is contending with two factors which somewhat seriously menace its chances of rapid universal adoption in cases of prostatic trouble. These factors are, on the one hand, the undeniably high mortality following it, and, on the other, the failure of the operation in a not inconsiderable number of the cases to remove the bladder symptoms. In regard to the mortality, the chief causes of death in those cases of which there are published records have been hæmorrhage and septic or pyæmic absorption. The hæmorrhage occurs from the prostatic plexus of veins, and is not easily controlled. The septic mischief takes origin in the wound bathed in the urine, and, considering the stinking and foully septic condition of the urine in most of the cases calling for the operation, the occurrence of sepsis can hardly be a matter of surprise. The failure of the operation to give relief from the bladder symptoms may be total or partial. In either case, to again quote the published accounts, the failure may be owing to the contracted and thickened, or dilated and atonic, condition of the bladder due to the months or years of previous strain and cystitis, but it would seem to be owing, in a certain number of cases, to inadequate and incomplete removal of the offending prostatic tissue. The operations at present practised are three in number-the supra-pubic method, the operation by the perineal route, and a combination of these two During the past five years it has been my lot to see, in this country and on the Continent, fourteen prostatectomies by one or other of these methods, and also to have the opportunity of observing and examining cases on which the operation had been performed at dates ranging from a few weeks to three years previously. Of those cases I have seen I can recall several which have not been published. These had fatal, or only less unfortnnate, results. That serious risk from hæmorrhage does occur, and that septicæmia and pyæmia, with or without fatal issue, are by no means rare, I know from personal observation. That insufficient removal is a common cause of ultimate failure several cases I have examined clearly demonstrate. Finally, I have seen so much tearing up of the neck of the bladder and urethra in the course of the operation that distortion and stricture of the channel, with or without permanent perineal fistula, and fistula, without stricture, have resulted.

Amongst such untoward possibilities, however, there stands out the fact that in judiciously-selected and suitable cases the operation in a large number of instances gives most satisfactory results. This being so, the natural endeavour is to so obviate or minimise the chances of such unfortunate results as to give the operation in the future both a better record in the restricted class of cases it is at present applied to, and a considerably wider field of applicability so as to include cases of more advanced mischief than are at present admitted. It will be obvious that such endeavour will involve attention to the following points: (1) prevention or lessening of the bæmorrhage; (2) prevention of septic or pyæmic absorption ; (3) deliberate, complete, or at least pretty extensive, removal of the prostatic tissue; and (4) avoidance of extensive tearing out of portions of the bladderneck and deep urethra. Working along these lines, after several experimental operations on the cadaver, it seemed to me that there was a method of operating by which the above ends might be more nearly attained than by any of the hitherto-published operations. This method I have had the opportunity of twice applying to actual cases, and, while it is as yet too early to express a definite opinion as to the ultimate amount of benefit obtained, the immediate results of the operation have been so satisfactory that I have little hesitation in thus early submitting it for fuller trial at the hands of those to whom opportunity may offer. Briefly, the operation is a submucous removal of the entire prostate, or as much of it as may be deemed necessary, by a combined supra-pubic and perineal operation. The technique of the operation is as follows :-A suprapubic cystotomy is performed; no rectal bag is employed for this on account of the subsequent proceedings. All bleeding points in the parietal incision are secured and the wound dusted with iodoform before the bladder is opened. The incision in the bladder wall must be a free one, and the wall of the viscus is secured to the skin by four sutures. The bladder is then carefully and repeatedly douched with warm carbolic solution ( 1 in 200), phosphatic concretions on the walls being removed with a lithotomy scoop. The viscus is then partially filled with the carbolic solution and the patient tied up in the lithotomy position. The second part of the operation consists in the removal of the prostate through a modified median lithotomy wound. An ordinary bongie or sound is passed and given to an assistant. The left forefinger in the rectum, an incision is made in the perineal raphe, and gradually deepened till the apex of the prostate is reached but without penetrating the urethra or bladder. The rectum is carefully separated from the posterior surface of the prostate, and a vertical incision is then made through the posterior and inferior part of the prostate capsule. The capsule is then gradually shed off the gland to either side by means of some blunt instrument like a periostenm elevator, the assistant meantime pressing the prostate down into the perineal wound with his fingers, introduced into the bladder by the supra-pubic opening. (If sufficient room for this isolating of the prostate has not been afforded by the median perineal wound it may be obtained by supplementing the median incision by a lateral one, somewhat on the lines of Dittel's, and curving ontwards and backwards from the posterior end of the median cut to a point between the anus and the posterior end of the ischial tuberosity, nearer the former than the latter. This may be done on one or both sides.) All bleeding points being secured, the surgeon, after carefully washing his left index finger in carbolic solution, puts two fingers of the left hand into the bladder from the supra-pubic wound, and, pressing the prostate (now pretty freely movable) down into the perineal wound, removes, by the fingers of his right hand in the perineum, the entire prostate, or as much of it as he deems necessary to relieve the neck of the bladder from all pressure, and bring it down to a level with the postprostatic pouch in the base of the bladder, judging the amount to be removed by manipulation of the parts between the fingers of the two hands. Should the prostatic tissue be more than usually tough and resistant, the fingers of the right hand may be supplemented by a blunt periosteum elevator or other similar instrument, or even by a Volkmann's spoon carefully used. During the entire operation neither bladder nor urethra is opened further than is involved in the supra-pubic incision. After enucleation of the prostate is complete the sound or bougie is withdrawn and a large-eyed, short-beaked metal catheter (such as a lithotrity evacuating catheter) or a large elastic-gum catheter coudé is introduced and tied in. The perineal wound, which forms a cavity of some mag nitude, is douched with weak carbolic solution; carefully dried with gauze or sponges, and firmly stuffed with iodoform gauze. The four stitches in the supra-pubic 